\title{
Prevalence and pattern of refractive errors among Saudi adults
}

\author{
Mujeeb Ur Rehman Parrey ${ }^{1}$, Ekramy Elmorsy²
}

\begin{abstract}
Background \& Objectives: Refractive Errors (RE) are responsible for major portion of the treatable visual impairment and avoidable blindness in the world. The prevalence of RE varies with age, gender, ethnicity, geographical locations and also from time to time due to progresse in eye care services. We aimed to study the prevalence of RE and assess their patterns among Saudi adults of Arar city, the capital of Northern Border Region of Saudi Arabia.

Methods: This is a cross-sectional, population-based study. A total number of 966 Saudi adults aged 16 to 39 years were enrolled. The patterns of their RE were studied through auto-refraction evaluation.

Results: The prevalence of RE was $45.8 \%$. The most frequent type of RE was myopia in $24.4 \%$, followed by hyperopia $11.9 \%$ and astigmatism in $9.5 \%$ cases. Ages and genders significantly affect the prevalence of the different patterns of RE (0.033 and 0.012 , respectively).

Conclusion: The prevalence of RE in Arar city is slightly lower than that previously published in the same targeted age group. Myopia is the main RE. More awareness programs, especially among young adults are recommended for better outcomes.
\end{abstract}

KEYWORDS: Ametropia, Astigmatism, Emmetropia, Hyperopia, Myopia, Refractive error, Visual impairment.

Abbreviations: RE: Refractive Error, SE: Spherical Equivalent, VA: Visual Acuity, VI: Visual Impairment.

doi: https://doi.org/10.12669/pjms.35.2.648

How to cite this:

Parrey MUR, Elmorsy E. Prevalence and pattern of refractive errors among Saudi adults. Pak J Med Sci. 2019;35(2):394-398. doi: https://doi.org/10.12669/pjms.35.2.648

This is an Open Access article distributed under the terms of the Creative Commons Attribution License (http://creativecommons.org/licenses/by/3.0), which permits unrestricted use, distribution, and reproduction in any medium, provided the original work is properly cited.

\section{INTRODUCTION}

When the parallel rays of light coming frominfinity are focused on the retina with the accommodation of the eye at rest it indicates the normal refractive status of the eye called as emmetropia. An emmetropic

1. Dr. Mujeeb Ur Rehman Parrey, Ph.D.

Department of Surgery,

2. Dr. Ekramy Elmorsy, MD.

Department of Pathology,

1, 2: Faculty of Medicine,

P.O. Box-1321,

Northern Border University,

Arar, Kingdom of Saudi Arabia.

Correspondence:

Dr. Mujeeb Ur Rehman Parrey; Ph.D.

Faculty of Medicine, Northern Border University,

Arar; Kingdom of Saudi Arabia.

E-mail: drparrey@gmail.com

* Received for Publication:

October 31, 2018

* Corrected and Edited:

* Accepted for Publication:

February 4, 2019 eye will therefore make a clear image of the distant object without any internal adjustment of its optics. If the rays of light with accommodation of the eye at rest are not focused exactly on the retina the condition indicates an error of refraction, which is referred to as ametropia. ${ }^{1}$ Refractive error (RE) is classified into myopia, hyperopia and astigmatism. In myopia with accommodation relaxed, light rays from an object at infinity are focused in front of retina and in hyperopia behind the retina while as in astigmatism the light rays do not focus at a single point because of variations in the curvature of the cornea or lens at different meridians. ${ }^{2}$

REcan betreated by optical methods likecorrective glasses and contact lenses or surgical methods like LASIK (laser-assisted in situ keratomileusis) or PRK (photorefractive keratectomy).

Lack of knowledge and awareness about $\mathrm{RE}^{3}$, non-recognition of the problem at personal or family level, as well as at community and public health 
level; economic and social barriers and availability and affordability of eye health services are the main reasons for RE to remain uncorrected..$^{4,5} \mathrm{RE}$ have serious impact on economy of many countries of the world. 6,7 Many studies conducted abroad indicate that the prevalence of RE exhibits significant variation across geographic, racial, age, gender and ethnic boundaries, which has an enormous impact on the strategies utilized in addressing the problem of RE. ${ }^{8,9}$ This is more likely in people living in countries with limited resources and poor access to the eye care services. Studies conducted in some parts of Saudi Arabia indicate that RE are among the leading causes of VI. ${ }^{10-12}$ In Saudi Arabia, RE were studied considering either mainly the pediatric population ${ }^{13-16}$ or particular population groups like students undergoing higher education. ${ }^{17}$

Although a large number of studies pertaining to RE have been conducted in many parts of the world, the comparison of the data remains difficult owing to lack of consistency in methods and definitions used for identifying and measuring RE. However, prevalence and patterns of RE in Arar city have not been studied yet. The data from the current study shall fill the gap to evaluate the current state of the problem in Arar city with better guidelines for the future strategies to overcome the burden of RE.

\section{METHODS}

This cross-sectional, population-based study was conducted from January $1^{\text {st }}, 2018$ to September $1^{\text {st }}$, 2018. A sample from the general population was randomly collected at screening camps held in the main shopping mall of Arar city where a temporary eye clinic was installed for three consecutive days. Persons with any previous history of refractive surgery were excluded from this study. The participants were further evaluated at the Central Hospital of Arar city. Visual Acuity (VA) was tested on VA Auto Chart Projector (TOPCON ACP-8; Japan) and refraction without cyloplegia was performed on auto-refractor (Topcon KR-8900; Japan).

The RE was classified using the Spherical equivalent (SE), which is the sum of the value of the sphere and half of the cylindrical value. ${ }^{18}$ Emmetropia was attributed to SE between $-0.50 \mathrm{D}$ and $+0.50 \mathrm{D}$, myopia to $\mathrm{SE} \leq-0.50 \mathrm{D}$, hyperopia to $\mathrm{SE} \geq+0.50 \mathrm{D}$ and astigmatism to any cylindrical error of at least 0.5 $\mathrm{D}$ without reference to the axis. Myopia was further categorized as low $(\geq-0.50 \mathrm{D}$ and $<-3.00 \mathrm{D})$, moderate $(\geq-3.00 \mathrm{D}$ and $<-6.00 \mathrm{D})$ and high $(\geq-6.00 \mathrm{D})$. Hyperopia was further categorized as low to moderate $(\geq+0.50 \mathrm{D}$ and $<+3.00 \mathrm{D})$ and high $(\geq+3.0 \mathrm{D})$ hyperopia. Astigmatism was further categorized as low to moderate (cylinder error of $\geq 0.50 \mathrm{D}$ and $<3.00$ D) and high ( $\geq 3.00 \mathrm{D})$ astigmatism. Simple myopic astigmatism was defined as plano sphere $(<-0.5 \mathrm{D}$ to $<+0.5 \mathrm{D})$ and cylinder of $\geq-0.50 \mathrm{D}$, simple hyperopic astigmatism was defined as plano sphere $(<$ $-0.5 \mathrm{D}$ to $<+0.5 \mathrm{D}$ ) and cylinder of $\geq+0.50 \mathrm{D}$ ); compound myopic astigmatism was defined as sphere of $\geq-0.5 \mathrm{D}$ and cylinder of $\geq-0.50 \mathrm{D}$, compound hyperopic astigmatism was defined as sphere of $\geq$ $+0.5 \mathrm{D}$ and cylinder of $\geq+0.50 \mathrm{D}$. Astigmatism was defined as mixed if the sphere was positive $(>+0.5$ D) and cylinder value was negative $(>-0.50 \mathrm{D})$ or vice versa and the cylinder value was greater than a sphere.

Data Analysis: Data was revised, coded, entered, tabulated, and analyzed using SPSS version 20. Chisquare was used to study the significance of association. Statistical significance was kept constant at $\mathrm{P}<0.05$.

This study was approved by the ethical committee of Deanship of Scientific Research, Northern Border University. Informed written consent was obtained from all participants involved in this study. Financial or any other compensations were not offered to any of the participants.

\section{RESULTS}

A total of 966 Saudi adults were enrolled in the current study [485 females (48.7\%) and 481 males $(51.3 \%)]$. The mean age of the studied population was $27.48( \pm 6.32)$ years with a range of 16-39 years old. The prevalence of RE was estimated to be $45.8 \%$. The commonest type of RE was myopia (SE

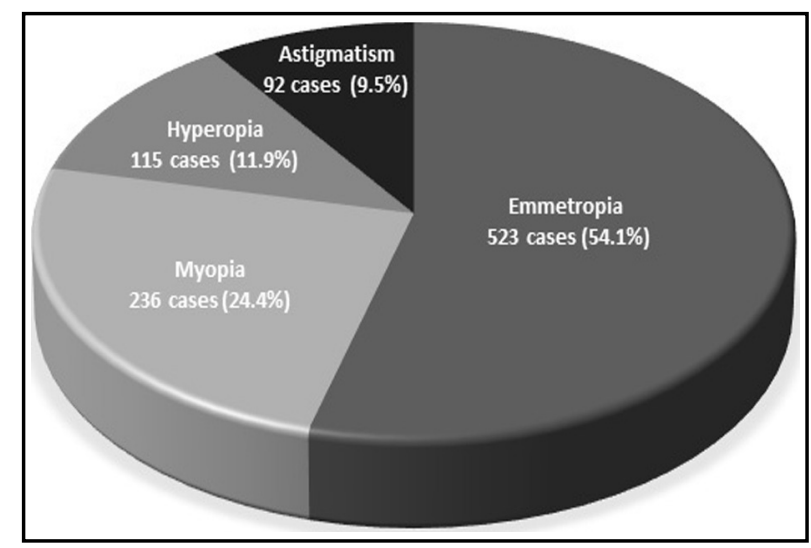

Fig.1: Refractive error among the studied population. Emmetropia was attributed to SE between $-0.50 \mathrm{D}$ and $+0.50 \mathrm{D}$, myopia to $\mathrm{SE} \leq-0.50 \mathrm{D}$, hyperopia to $\mathrm{SE} \geq+0.50 \mathrm{D}$ and astigmatism to any cylindrical error of $\leq-0.50 \mathrm{D}$ or $\geq+0.50 \mathrm{D}$ with $\mathrm{SE}$ in the emmetropia range without reference to the axis. 
Table-I: Pattern of refractive error in relation to gender.

\begin{tabular}{lcccc}
\hline Type of refractive error & Total & Females & Males & P-value \\
\hline Emmetropia & $523(54.1 \%)$ & $240(24.8 \%)$ & $283(29.3 \%)$ \\
Myopia & $67(6.9)$ & $42(4.3 \%)$ & $25(2.6 \%)$ \\
Hyperopia & $31(3.2 \%)$ & $16(1.7 \%)$ & $15(1.6 \%)$ \\
Simple myopic astigmatism & $76(7.9 \%)$ & $32(3.3 \%)$ & $44(4.6 \%)$ & $0.0123^{*}$ \\
Simple hyperopic astigmatism & $16(1.7 \%)$ & $9(0.9 \%)$ & $7(0.7 \%)$ & $17.93,7$ \\
Compound myopic astigmatism & $166(17.2 \%)$ & $101(10.5 \%)$ & $65(6.7 \%)$ & $4(0.4 \%)$ \\
Compound hyperopic astigmatism & $8(0.8 \%)$ & $4(0.4 \%)$ & $38(3.9 \%)$ & \\
Mixed astigmatism & $79(8.2 \%)$ & $41(4.2 \%)$ & $481(49.8 \%)$ \\
\hline Totals & $966(100 \%)$ & $485(50.2 \%)$ & \\
\hline
\end{tabular}

$\leq-0.5 \mathrm{D}$ ) in $24.4 \%$ followed by hyperopia (SE $\geq 0.5 \mathrm{D}$ ) in $11.9 \%$ and simple astigmatism (with SE between $0.5 \mathrm{D}$ and $-0.5 \mathrm{D}$ ) in $9.5 \%$ cases (Fig.1).

Regarding the genders of participants, there was a significant difference between the males and females in prevalence of RE (Table-I). Pertaining to the age (Table-II), myopia was found to be slightly more common in age group $\geq 25$, while as hyperopia in $>25(p=0.033)$. Grading of RE severity in the studied population is shown in Table-III. Cases with astigmatism were classified according to their SE (Table-I and II) and the commonest type was found to be the compound myopic astigmatism.

Cases with $\mathrm{SE} \leq-0.5 \mathrm{D}$ were classified according to the cylindrical correction to simple myopia (cylinder $>-0.5 \mathrm{D}$ and $<0.5 \mathrm{D}$ ), compound myopic stigmatism (cylindrical correction $\leq-0.5 \mathrm{D}$ ) and mixed myopic stigmatism (cylindrical correction $\geq 0.5 \mathrm{D}$ ) (Table-IV). Cases with SE $\geq 0.5 \mathrm{D}$ were classified according to the cylindrical correction to simple hyperopia (cylinder $>-0.5 \mathrm{D}$ and $<0.5 \mathrm{D}$ ), compound hyperopic stigmatism (cylinder $\geq 0.5 \mathrm{D}$ ) and mixed hyperopic stigmatism (cylinder $\leq-0.5 \mathrm{D})$ (Table-V).

\section{DISCUSSION}

This study has evaluated the patterns and prevalence of RE in Arar city. The prevalence of RE was estimated to be $45.8 \%$. The commonest type of RE was myopia (SE $\leq-0.5 \mathrm{D}$ ) in $24.4 \%$ followed by hyperopia (SE $\geq 0.5 \mathrm{D}$ ) in $11.9 \%$ and simple astigmatism (with SE between $0.5 \mathrm{D}$ and $-0.5 \mathrm{D}$ ) in $9.5 \%$ cases. Both genders and age groups of participants showed significant effect on patterns and prevalence of the different RE types.

No definite published data regarding the prevalence of RE is avaliable in Saudi Arabia. The published data were based only on school children and adolescents. ${ }^{19}$ The prevalence of RE in Saudi adults of Arar city is $45.8 \%$ which is lower than the prevalence of RE $(72.2 \%)$ among female students of Medicine and Pharmacy Schools in Quassin University as reported by Albatanony. ${ }^{20}$ Another study from Quassim estimated the prevalence of $\mathrm{RE}$ as $58.6 \%$ among the male medical students of Qassim University. ${ }^{17}$ This higher prevalnce may be due to faulty abuse of vision during prolonged hours of studying among the medical students

Table-II: Pattern of refractive errors in relation to age groups.

\begin{tabular}{lcccc}
\hline Type of refractive error & Total & $\geq 25$ yrs. & $>25$ yrs. & P-value \\
\hline Emmetropia & $523(54.1 \%)$ & $293(30.3 \%)$ & $228(23.6 \%)$ & \\
Myopia & $67(6.9)$ & $37(3.8 \%)$ & $30(3.1 \%)$ & \\
Hyperopia & $31(3.2 \%)$ & $11(1.1 \%)$ & $20(2 \%)$ & \\
Simple myopic astigmatism & $76(7.9 \%)$ & $34(3.5 \%)$ & $32(3.3 \%)$ & $0.033^{*}$ \\
Simple hyperopic astigmatism & $16(1.7 \%)$ & $7(0.7 \%)$ & $9(0.9 \%)$ & $15.17,7$ \\
Compound myopic astigmatism & $166(17.2 \%)$ & $76(7.9 \%)$ & $90(9.3 \%)$ & \\
Compound hyperopic astigmatism & $8(0.8 \%)$ & $3(0.3 \%)$ & $5(0.5 \%)$ & \\
Mixed astigmatism & $79(8.2 \%)$ & $33(3.4 \%)$ & $46(4.8 \%)$ & \\
\hline Totals & $966(100 \%)$ & $485(50.2 \%)$ & $481(49.8 \%)$ & \\
\hline
\end{tabular}


Mujeeb Ur Rehman Parrey et al.

Table-III: Severity of refractive errors in relation to gender and age groups.

\begin{tabular}{|c|c|c|c|c|c|c|c|c|}
\hline$R E$ & Severity & Totals & Females & Males & P-value & $\geq 25$ yrs. & $>25$ yrs. & P-value \\
\hline \multirow{4}{*}{$\begin{array}{l}\frac{\pi}{2} \\
\frac{0}{2} \\
\sum\end{array}$} & Mild & $162(68.5 \%)$ & $132(55.9 \%)$ & $30(12.7 \%)$ & \multirow{4}{*}{$<0.0001$} & 77 (32.6\%) & $85(35.9 \%)$ & \multirow{4}{*}{0.0003} \\
\hline & Moderate & $60(25.4 \%)$ & $15(6.3 \%)$ & 45 (19.1\%) & & $46(19.5 \%)$ & $14(5.9 \%)$ & \\
\hline & Severe & $16(6.7 \%)$ & $12(5 \%)$ & $4(1.7 \%)$ & & $11(4.6 \%)$ & $5(2.1 \%)$ & \\
\hline & Totals & $236(100 \%)$ & $159(64.4 \%)$ & $77(35.6 \%)$ & & $134(56.8 \%)$ & $102(43.2 \%)$ & \\
\hline \multirow{3}{*}{ 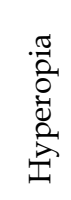 } & $\begin{array}{l}\text { Low to } \\
\text { moderate }\end{array}$ & $93(79.9 \%)$ & $48(41.3 \%)$ & $45(38.6 \%)$ & \multirow{3}{*}{1} & $31(29.6 \%)$ & $62(50.3 \%)$ & \multirow{3}{*}{1} \\
\hline & High & $22(19.1 \%)$ & $11(9.5 \%)$ & $11(9.5 \%)$ & & $7(6.1 \%)$ & $15(13 \%)$ & \\
\hline & Totals & $115(100 \%)$ & $59(51.3 \%)$ & $56(48.7 \%)$ & & $38(33 \%)$ & $77(67 \%)$ & \\
\hline \multirow{3}{*}{ 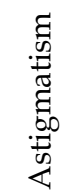 } & $\begin{array}{l}\text { Low to } \\
\text { moderate }\end{array}$ & $324(94 \%)$ & $147(42.6 \%)$ & $177(57.4 \%)$ & \multirow{3}{*}{0.652} & $175(50.7 \%)$ & $139(49.3 \%)$ & \multirow{3}{*}{0.068} \\
\hline & High & $21(6 \%)$ & $11(3.2 \%)$ & $10(2.8 \%)$ & & $7(2 \%)$ & $14(4 \%)$ & \\
\hline & Totals & 345 (100\%) & $158(45.8 \%)$ & $187(54.2 \%)$ & & $182(52.8 \%)$ & $153(47.2 \%)$ & \\
\hline
\end{tabular}

Kumar et al., ${ }^{21}$ and Basu et al., ${ }^{22}$ In an another study conducted in Riyadh, ${ }^{19}$ the prevealence of RE among adolescents (12-20 years) was estimated to be $55.5 \%$ which is also higher than the present prevelence. In the nearby country Jordan, the prevalence of RE among adult population aged (17-40 years) was estimated to be around 60\% (Mallen et al, 2005). ${ }^{23}$ Internationally, the prevalence in USA was reported to be around $72 \%$ in civilain population aged above 12 years (Vitale et al., 2008). ${ }^{24}$ This higher prevalence in USA may be due to the elderly age group (above 40 years) in their study.

In the current study myopia was the commonest type of RE. This is in accordance with some recent studies conducted in $\mathrm{KSA}^{17,19}$ and abroad. ${ }^{25,26}$ In Europe the greatest burden of RE is due to myopia. ${ }^{27}$ While other data showed higher prevalence of astigmatism. ${ }^{28,29}$ Higher prevalence of hyperopia is usually seen in studies targeting elder age groups than our study age range. ${ }^{27,30}$ However, all these differences regarding the prevalence of the different patterns of RE may be related to the difference in the studied populations, methods of study and ages of the studied groups.

As regards the effect of age on the patterns of RE, our data showed that myopia was more prevalent among participants aged $<25$ years, while hyperopia was more dominant in the elderly participants. This is in line with the previously published data. ${ }^{17,25-27,30}$

Regarding gender the current results had found that myopia was more common in females. This is in accordance with the other studies as Katz et al. $(1997)^{31}$ and Czepita et al. (2007)..$^{32}$

\section{CONCLUSION}

To the best of our knowledge, this is the first research focused on RE of Saudi adult population to evaluate the current state of health service and

Table-IV: Classification of cases with SE $\leq-0.5 \mathrm{D}$ among the studied population.

\begin{tabular}{lc}
\hline SE and cylindrical lenses & Number of cases \\
\hline Simple myopia (cylinder $>-0.5 \mathrm{D}$ and $<0.5 \mathrm{D})$ & $67(28.4 \%)$ \\
Compound myopic stigmatism (cylinder $\leq-0.5 \mathrm{D})$ & $166(70.3 \%)$ \\
Mixed myopic stigmatism (cylinder $\geq 0.5 \mathrm{D})$ & $3(1.3 \%)$ \\
\hline Total & $236(100 \%)$ \\
\hline Table-V: Classification of cases with SE $\geq 0.5 \mathrm{D}$ among the studied population. \\
\hline SE and cylindrical lenses & Number of cases \\
\hline Simple hyperopia (cylinder $>-0.5 \mathrm{D}$ and $<0.5 \mathrm{D})$ & $31(26.9 \%)$ \\
Compound hyperopic stigmatism (cylinder $\geq 0.5 \mathrm{D})$ & $8(6.9 \%)$ \\
Mixed hyperopic stigmatism (cylinder $\leq-0.5 \mathrm{D})$ & $76(66 \%)$ \\
\hline Total & $115(100 \%)$ \\
\hline
\end{tabular}


to plan properly according to our results for better control of the problem in Northern Border Region. The vital epidemiological data on prevalence and patterns of RE from this study are important for planning and improvement of screening and rehabilitation programs for better outcomes of the cases of refractive errors in Arar.

Acknowledgements: We express gratitude to the Deanship of Scientific Research, Northern Border University for supporting this project.

Grant Support E Financial Disclosures: This study was funded by Deanship of Scientific Research, Northern Border University.

\section{REFERENCES}

1. Khurana AK. Theory and Practice of Optics and Refraction. $2^{\text {nd }}$ edition Reed Elsevier India Pvt. Ltd P 61-62; 2008.

2. Liesegang TJ, Gregory LS, Cantor LB. Basic and Clinical Science Course- Am Acad Ophthalmol. San Francisco, ed, 2007.

3. Rosman M, Wong TY, Wong W, Wong ML, Saw SM. Knowledge and beliefs associated with refractive errors and undercorrection: the Singapore Malay Eye Study. Br J Ophthalmol. 2009;93(1):4-10. doi: 10.1136/bjo.2007.132506.

4. Resnikoff S, Donatella P, Silvio PM, Gopal PP. Global magnitude of visual impairment caused by uncorrected refractive errors in 2004 . Bulletin of the World Health Organization 2008;86:63-70.

5. Jeganathan VSERobin AL, Woodward MA. Refractive error in underserved adults: causes and potential solutions. Curr Opin Ophthalmol.2017;28(4):299-304. doi:10.1097/ICU.0000000000000376.

6. Fricke TR, Holden BA, Wilson DA, Schlenther G, Naidoo KS, Resnikoff S, et al. Global cost of correcting vision impairment from uncorrected refractive error. Bull World Health Organ. 2012;90(10):728-738. doi: 10.2471/BLT.12.104034.

7. Smith TS, Frick KD, Holden BA, Fricke TR, Naidoo KS. Potential lost productivity resulting from the global burden of uncorrected refractive error. Bull World Health Organ. 2009;87(6):431e 437. doi: 10.2471/BLT.08.055673

8. Zhao J, Pan X, Sui R, Munor SR, Spertudo RD, Ellwein LB. Refractive error study in children: Results from Shunyi District, China. Am J Ophthalmol. 2000;129:427-435.

9. Naidoo KS, Holden B, Sweeney D, Colvin M. Design of a blindness prevention reporting and planning tool utilising the results of a population based study of visual impairment in a health district in Kwazulu-Natal. Invest Ophthalmol Vis Sci. 2007;48(13):327.

10. Al-Shaaln FF, Bakrman MA, Ibrahim AM, Aljoudi AS. Prevalence and causes of visual impairment among Saudi adults attending primary health care centers in northern Saudi Arabia. Ann Saudi Med. 2011;31(5):473-480. doi: 10.4103/0256-4947.84624.

11. Parrey MU, Alswelmi FK. Prevalence and causes of visual impairment among Saudi adults. Pak J Med Sci. 2017;33(1):167-171. doi: $10.12669 /$ pjms.331.11871.

12. Tabbara KF, El-Sheikh HF, Shawaf SS. Pattern of childhood blindness at a referral center in Saudi Arabia. Ann Saudi Med. 2005;25(1):18-21.

13. Alrahili NHR, Jadidy ES, Alahmadi BSH, Abdula'al MF, Jadidy AS, Alhusaini A, et al. Prevalence of uncorrected refractive errors among children aged 3-10 years in western Saudi Arabia. Saudi Med J. 2017;38(8):804-810. doi: 10.15537/smj.2017.8.20412.

14. Al Wadaani FA, Amin TT, Ali A, Khan AR. Prevalence and pattern of refractive errors among primary school children in Al Hassa, Saudi Arabia. Glob J Health Sci. 2012;5(1):125-34. doi: 10.5539/gjhs. v5n1p125.

15. Al-Rowaily MA. Prevalence of refractive errors among pre-school children at King Abdulaziz Medical City, Riyadh, Saudi Arabia. Saudi J Ophthalmol. 2010;24(2):45-48. doi: 10.1016/j.sjopt.2010.01.001.

16. Al-Tamimi ER, Shakeel A, Yassin SA, Ali SI, Khan UA. A clinicbased study of refractive errors, strabismus, and amblyopia in pediatric age-group. J Family Community Med. 2015;22(3):158-162. doi: $10.4103 / 2230-8229.163031$.
17. Al-Rashidi SH, Albahouth AA, Althwini WA, Alsohibani AA, Alnughaymishi AA, Alsaeed AA, et al. Prevalence Refractive Errors among Medical Students of Qassim University, Saudi Arabia: Cross-Sectional Descriptive Study. Open Access Maced J Med Sci. 201819;6(5):940-943. doi: 10.3889/oamjms.2018.197.

18. Althomali TA. Relative Proportion of Different Types of Refractive Errors In Subjects Seeking Laser Vision Correction. Open Ophthalmol J. 2018;12:53-62. doi: 10.2174/1874364101812010053. eCollection 2018.

19. Alsaqr A, Abu Sharha A, Fagehi R, Almutairi A, Alosaimi S Almalki A, et al. The visual status of adolescents in Riyadh, Saudi Arabia: a population study. Clin Ophthalmol. 2018; 12: 965-972. Published online 2018 May 22. doi: 10.2147/OPTH.S162319

20. Al-Batanony MA. Refractive Errors among Saudi Medical and Pharmacy Female Students: A Questionnaire Survey Study. J Adv Med Pharmac Sci. 2016;7(1):1-8. Article no.JAMPS.24633.

21. Kumar N, Jangra B, Jangra MS, Pawar N. Risk factors associated with refractive error among medical students. Int. J Community Med Public Health. 2018;5(2):634-638. doi: 10.18203/2394-6040. ijcmph20170241.

22. Basu M, Ray S, Mazumdar M, Gupta AK, Sengupta P, Chatterjee S. Refractive Errors and its Determinants among Medical Students of Kolkata: A Descriptive Study. Int J Prev Pub Health Sci. 2016;2(1). doi: 10.17354/ijpphs/2016/20.

23. Mallen EA, Gammoh Y, Al-Bdour M, Sayegh FN. Refractive error and ocular biometry in Jordanian adults. Ophthalmic Physiol Opt. 2005;25(4):302-309

24. Vitale S, Ellwein L, Cotch MF, Ferris FL 3rd, Sperduto R. Prevalence of refractive error in the United States, 19992004. Arch Ophthalmol. 2008;126(8):1111-1119. doi: 10.1001/ archopht.126.8.1111.

25. Foster PJ, Jiang Y. Epidemiology of myopia. Eye (Lond). 2014;28(2):202-208. doi: 10.1038/eye.2013.280.

26. Gomez-Salazar F, Campos-Romero A, Gomez-Campana H, CruzZamudio C, Chaidez-Felix M, Leon-Sicairos N, et al. Refractive errors among children, adolescents and adults attending eye clinics in Mexico. Int J Ophthalmol. 2017;10(5):796-802. doi: 10.18240/ ijo.2017.05.23.

27. Williams KM, Verhoeven VJ, Cumberland P, Bertelsen G, Wolfram C, Buitendijk GH, et al. Prevalence of refractive error in Europe: the European Eye Epidemiology (E(3)) Consortium. Eur J Epidemiol. 2015;30(4):305-315. doi: 10.1007/ s10654-015-0010-0.

28. Prema R, George R, Sathyamangalam Ve R, Hemamalini A, Baskaran M, Kumaramanickavel G, Catherine M, et al. Comparison of refractive errors and factors associated with spectacle use in a rural and urban South Indian Population. Indian J Ophthalmol. 2008;56(2):139-144.

29. Ferraz FH, Corrente JE, Opromolla P, Padovani CR, Schellini SA. Refractive errors in a Brazilian population: age and sex distribution. Ophthalmic Physiol Opt. 2015;35(1):19-27. doi: 10.1111/opo.12164.

30. Pan CW, Wong TY, Lavanya R, Wu RY, Zheng YF, Lin XY, et al. Prevalence and risk factors for refractive errors in Indians: the Singapore Indian Eye Study (SINDI). Invest Ophthalmol Vis Sci. 2011;52(6):3166-3173. doi: 10.1167/iovs.10-6210

31. Katz J, Tielsch JM, Sommer A. Prevalence and risk factors for refractive errors in an adult inner city population. Invest Ophthalmol Vis Sci. 1997;38(2):334-340.

32. Czepita D, Mojsa A, Ustianowska M, Czepita M, Lachowicz E. Role of gender in the occurrence of refractive errors. Ann Acad Med Stetin. 2007;53(2):5-7.

\section{Author's Contribution:}

MURP, EE: Conception, design and/or analysis and interpretation of data and Drafting the article or revising it critically for important intellectual content and final approval of the version to be published. 